\title{
Global imperatives and challenges facing the practice of neurology
}

\author{
Robert C. Griggs, MD \\ Bertrand Fontaine, MD, PhD \\ Gen Sobue, MD, PhD
}

\section{Summary}

The change in the practice of neurology from a diagnostic to a therapeutic specialty has empowered neurologists to make increasingly important decisions and recommendations for patients. With better understanding of disease pathogenesis and treatment has come the need to focus on disease prevention and the avoidance of treatment side effects. An increasingly automated and mechanized health care system has challenged us to integrate vast amounts of data that have a direct effect on patient risks and treatment, and to develop systems that avoid medical errors and allocate resources appropriately. It is imperative that we reaffirm the wisdom of clinical experience and judgment to inform our use of new technologies lest we lose the art of listening to and caring for the patient.

$\mathrm{I}$ $\mathrm{n}$ the years since the 3 of us began to practice, our specialty has changed from a largely diagnostic to a therapy-focused discipline. And as our diagnostic skills and technologies have improved, new opportunities and challenges have confronted us. Neurologists are able to make a definitive diagnosis for most of our patients, but now have new charges: to develop the approach to presymptomatic "disease" in order to prevent predictable diseases; to decide among 2 or more treatment options; and most challenging and troubling, to decide whether a patient "deserves" expensive treatments. We must learn how

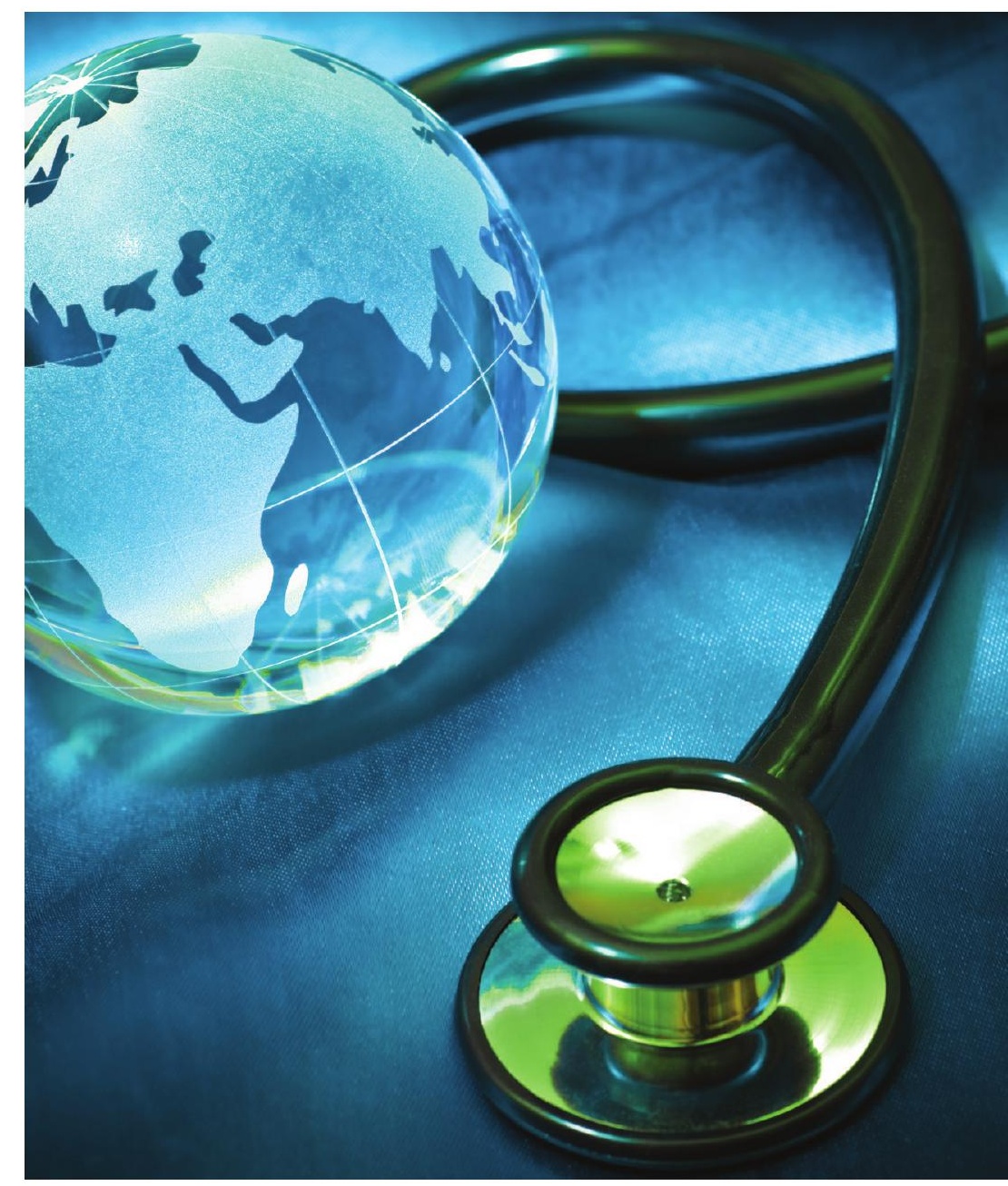

Department of Neurology (RCG), University of Rochester School of Medicine and Dentistry, Rochester, New York; Assistance Publique-Hopitaux de Paris (BF), Department of Neurology, Pitié-Salpêtrière Hospital, Paris, France, and Université Pierre et Marie Curie-INSERM-CNRS (BF), UMR 975-7225, Institut Cerveau Moelle-ICM, Pitié-Salpêtrière Hospital, Paris; and Department of Neurology (GS), Nagoya University Graduate School of Medicine, Nagoya, Japan.

Correspondence to: robert_griggs@urmc.rochester.edu 


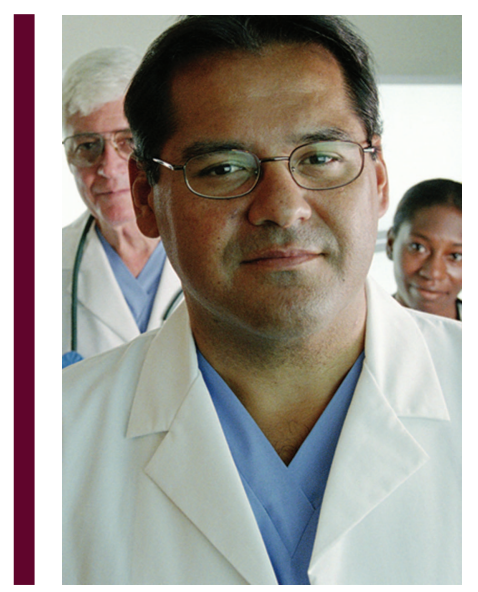

\section{Neurologic practice must adapt to information overload,} integration of bioinformatic data, and coordination of multiple providers in an increasingly mobile society.

to contend with vast amounts of data and, in the process, yield some of our cherished autonomy to develop and implement systems of care that detect and prevent errors. The practicing neurologist has the opportunity to contribute to clinical research that will develop evidencebased neurology and quality indicators that can inform the assessments of how well we are doing as clinicians. Participation in such research serves to improve clinical skills and quality of care. Set against the almost unlimited opportunities available to neurologists is the need to develop and promote approaches that will conserve resources, so that neurologic breakthroughs are affordable.

\section{Incidentalomas and other presymptomatic diseases}

Neurologists were often the "gatekeepers" for expensive technologies such as MRI scanning and genetic testing. As test availability has expanded and associated costs have decreased, such testing may be ordered by non-neurologists before their history and examination have framed a question that the study is, ideally, designed to answer. "Disease," such as an incidental, small tumor, unrelated to the patient's symptoms, is often detected by MRI, ${ }^{1,2}$ and 1,2 , or more genetic diseases may be "diagnosed" by whole genome sequencing ${ }^{3,4}$ at a time when there is as yet no evidence for symptoms (or treatments). Protecting patients from unnecessary "treatment" and from disclosure of such information to employers, insurance agencies, and others is an increasing challenge. Moreover, in such situations the neurologist's challenge is often to convince the patient and referring physician that the finding is not relevant to the patient's symptoms (difficult) or that the actual diagnosis is a disease process invisible by imaging or undetectable by molecular testing (sometimes virtually impossible). The old adage, "never order a test until you've decided what it will show" still guides neurologists but is alien territory to our non-neurologist colleagues.

\section{Disease prevention}

We already know how to prevent some neurologic diseases. Examples include many infectious diseases; stroke by primary and secondary prevention; anticonvulsant adverse effects, by testing for genetic risk factors; and traumatic brain injury by appropriate protection strategies. As we learn more about the environmental factors that trigger or accelerate genetic diseases we will soon have the ability to delay or prevent the development of these diseases. Eventually, gene-based therapies will enable us to prevent or delay the onset of malignancies, metabolic disorders, and many degenerative diseases.

\section{Challenges for disease prevention}

We know how to prevent vascular diseases of the heart and brain. ${ }^{5}$ Preventing atherosclerosis in patients who have not had a stroke (primary prevention) is the responsibility of all physicians but not the specific purview of neurologists. Preventing the progression of vascular disease and recurrent stroke in a patient who has had a brain infarction is the neurologist's job (secondary prevention). We have recognized this; we have examined how well we have done at 


\section{Table Primary prevention of stroke: Life's Simple Seven}

1. Never smoked or quit more than 1 year ago

2. Body mass index less than $25 \mathrm{~kg} / \mathrm{m}^{2}$

3. Physical activity at least 150 minutes (moderate intensity) or 75 minutes (vigorous) each week

4. Four to 5 key components of a healthy diet consistent with American Heart Association guidelines

5. Total cholesterol $<200 \mathrm{mg} / \mathrm{dL}$

6. Blood pressure $<120 / 80 \mathrm{~mm} \mathrm{Hg}$

7. Fasting blood glucose $<100 \mathrm{mg} / \mathrm{dL}$

Sacco RL. Achieving ideal cardiovascular and brain health: opportunity amid crisis: Presidential Address at the American Heart Association 2010 Scientific Sessions. Circulation 2011;123:2653-2657.

implementing secondary prevention strategies, ${ }^{6}$ but we have only begun to think about how we change patient behaviors to adopt a healthier lifestyle. The current American Heart Association (AHA) campaign to promote "Life's Simple Seven" (table) is currently championed by AHA President and neurologist Ralph Sacco, MD, FAAN. Dr. Sacco has emphasized that only 1 in 200 people in the United States actually adopt these guidelines and change their lifestyle. ${ }^{5}$ The challenge for neurologists is not only that of changing patient behavior but also changing physician behavior (neurologist and primary care physicians) to focus on and learn how to improve our success at secondary stroke prevention. ${ }^{7}$ Primary care physicians have invested in research on ways to change physician and patient behavior and to implement the approaches that work, and translated those results into reimbursement and recommendations and standards for patient care. ${ }^{8}$ Neurologists are just beginning to recognize and accept the challenge.

\section{Addressing health care disparities}

Our 3 countries - the United States, France, and Japan - have excellent but different health care systems. However, within the United States and France there are segments of society that differ widely in their access to and implementation of neurologic treatments. Looking at the neurologic care in low income countries in Africa, South America, and Asia, standard treatments for many neurologic diseases have not reached most of the population. Current world leaders of neurology have recognized and begun to focus on improving this situation. Moreover, the next generation of neurologists has tackled the challenges of going to low income areas to assess directly and begin to address the neurologic health care needs. The subspecialty of "international" or "global neurology" is a large and growing interest of medical students and residents entering our field. ${ }^{9110}$ Our countries have the responsibility to help create the approaches and resources that will support their interests.

\section{Practice guidelines, quality indicators, and patient outcomes}

The neurologist has always been the specialist that can listen to a patient's history and arrive at a diagnosis that eluded other physicians. The advent of new diagnostic tests has made this skill even more important even as they have made it possible to identify previously undetectable lesions or diseases. Clinical acumen and intuition have been our survival skill. However, we now confront an increasingly well-informed and sometimes hostile public who demand that we standardize diagnostic testing, develop treatment algorithms, and pursue "evidence-based medicine" to the exclusion of less standardized treatments. The American Academy of Neurology has committed to the development of practice guidelines to standardize treatment of as many neurologic diseases as possible ${ }^{11}$ and is rapidly introducing quality indicators for common diseases such as epilepsy, stroke, and Parkinson disease. ${ }^{12}$ These quality indicators will 


\section{Protecting patients from unnecessary "treatment" and from disclosure of such information to employers, insurance agencies, and others is an increasing challenge.}

soon be integrated and coordinated with outcome measures that assess our ability to give optimal care. This prospect is not appealing to physicians in general and neurologists in particular. Physicians resist efforts to standardize care despite evidence that the introduction of checklists improve patient outcomes ${ }^{13}$ and that reporting comparative data on outcomes improves patient survival. ${ }^{14}$

\section{Systems engineering of medicine}

The prevention of errors in practice has now become a focus of the American Academy of Neurology's energies. The development and engineering of standardized systems has enabled the airline industry to reduce errors and plane crashes dramatically. ${ }^{15}$ While patients are not airplanes, physicians are not airline pilots, and hospitals are not airports, the arguments for developing systematic approaches to error prevention are compelling. Neurologic practice must adapt to information overload, integration of bioinformatic data, and coordination of multiple providers in an increasingly mobile society.

\section{Deciding when and whom to treat}

Will we be able to afford the new treatments for neurologic diseases? There is a major difference in the costs of health care in the United States, France, and Japan. The United States spends $16 \%$ of GDP on health care, a percentage that is increasing rapidly, while France and Japan spend less. Their costs, as ours, are becoming unaffordable. In the United States, up to $31 \%$ of the health care dollar goes to the for-profit segment of health care ${ }^{16}$ and as much as $10 \%$ may be devoted to prevention of tort actions. ${ }^{17}$ However, even if these costs can be reduced, the relentless increase in health care costs will likely become unsustainable. Expensive treatments such as IV immunoglobulin for neuromuscular diseases are beginning to be subject to standardized guidelines for use that control payment in France and Japan. ${ }^{18}$ Such prioritization of resource allocation is obviously essential, and will need to include discontinuation of medications when they are no longer effective. The practicing neurologist will also need to focus on other steps to control costs: 1) avoiding unnecessary testing; 2) devising lower cost care systems that prevent or shorten expensive in-hospital care; and 3) basing treatment decisions on metrics that reflect patient quality of life and avoiding futile but expensive interventions. As we have become skilled at treating diseases we have also created an increasing number of resource-intensive, less able people. Providing for these persons imposes still another cost on society, even though these costs are not considered "health care."

\section{Training the next generation of practicing neurologists}

It remains of the greatest importance for senior clinician/educators to teach the next generation the skill of listening to the patient and letting the history and examination tell us the diagnosis. This must be coupled with the ability to question the relevance of unpredicted laboratory findings to the patient's problems. The next generation also needs to be trained in clinical research methods, in communication skills, and in cost/benefit decision-making. Practicing neurologists (and their patients) benefit from participation in clinical research in many ways: 1) participation in trials contributes to the care of patients with conditions for which there are still suboptimal treatment options; 2) involvement in research serves to make the investigator familiar with advances in the field; 3) the quality of patient care is improved when the physician is involved in clinical research; and 4) the funding of the research often subsidizes the poorly reimbursed cognitive care that makes up the bulk of a neurologist's practice. 
Current and future residents will be sufficiently sophisticated in information technology that they will have relatively little difficulty making optimum use of the electronic health record and adapting to the system engineering it will facilitate. But they, like we ourselves, will need constant reminders that what patients crave is an attentive listener, focused on them as a person, tailoring treatment and advice to their specific complaints. As argued passionately and eloquently by AAN past-President Steve Sergay, “...doctoring faces many challenges..., all potentially imperiling our professional soul or ethos of life as doctors.” Dr. Sergay further asserts that, "We must return our principal attention to humanity to ensure that ill humans will always be more than integers on an economic chart." ${ }^{19}$ This advice from the consummate practicing neurologist cannot be overemphasized.

\section{REFERENCES}

1. Katzman GL, Dagher AP, Patronas NJ. Incidental findings on brain magnetic resonance imaging from 100 asymptomatic volunteers. JAMA 1999;282:36-39.

2. Grossman JI, Bernat JL. Incidental research imaging findings: Pandora's costly box. Neurology 2004; 62:849-850.

3. Laloui K, Wary C, Carlier RY, Hogrel JY, Caillaud C, Laforet P. Making diagnosis of Pompe disease at a presymptomatic stage: to treat or not to treat? Neurology 2011;77:594-595.

4. Kwon JM, Steiner RD. "I'm fine; I'm just waiting for my disease": the new and growing class of presymptomatic patients. Neurology 2011;77:522-523.

5. Sacco RL. Achieving ideal cardiovascular and brain health: opportunity amid crisis: Presidential Address at the American Heart Association 2010 Scientific Sessions. Circulation 2011;123:2653-2657.

6. Holloway RG, Benesch C, Rush SR. Stroke prevention: narrowing the evidence-practice gap. Neurology 2000;54:1899-1906.

7. Bushnell CD, Olson DM, Zhao X, et al. Secondary preventive medication persistence and adherence 1 year after stroke. Neurology 2011;77:1182-1190.

8. Flodgren G, Eccles MP, Shepperd S, Scott A, Parmelli E, Beyer FR. An overview of reviews evaluating the effectiveness of financial incentives in changing healthcare professional behaviours and patient outcomes. Cochrane Database System Review 2011;7:CD009255.

9. Galetta SL, Jozefowicz RF, Avitzur O. Advances in neurological education: a time to share. Ann Neurol 2006;59:583-590.

10. Dahodwala N. Neurology education and global health: my rotation in Botswana. Neurology 2007:68; E15-E16.

11. Getchius TSD, Moses LK, French J, Gronseth GS, England JD, Miyasaki J. AAN guidelines: a benefit to the neurology. Neurology 2010;75:1126-1127.

12. Cheng EM, Tonn S, Swain-Eng R, et al. Quality improvement in neurology: AAN Parkinson's disease quality measures. Neurology 2010;75:2021-2027.

13. Haynes AB, Weiser TG, Berry WR, et al. A surgical safety checklist to reduce morbidity and mortality in a global population. N Engl J Med 2009;360:491-499.

14. Gawande A. The bell curve. In: Better: A Surgeon's Notes on Performance. New York: Metropolitan Books; 2007: 201-230.

15. Gawande A. The Checklist Manifesto: How to Get Things Right, edition 1. New York: Picador; 2011.

16. Woolhandler S, Campbell T, Himmelstein DU. Costs of health care administration in the United State and Canada. N Engl J Med. 2003;349:768-775.

17. Issue Brief I: Malpractice liability, defensive medicine, and health care costs: VITA Advisors, LLC, 2009. Available at: http://vitaadvisors.com/wordpress/wp-content/uploads/2009/09/MalpracticeA.pdf. Accessed September 2, 2011.

18. Ikegami N, Campbell JC. Health care reform in Japan: the virtues of muddling through. Health Affairs 1999; 18:56-75.

19. Sergay SM. Doctoring 2009: embracing the challenge. Neurology 2009;73:1234-1239.

\section{DISCLOSURES}

Dr. Griggs serves as Chair of the Executive Committee of the Muscle Study Group, which receives support from pharmaceutical companies; has served on scientific advisory boards for The National Hospital Queen Square and PTC Therapeutics, Inc.; serves on the editorial boards of NeuroTherapeutics and Current Treatment Opinions in Neurology and as Correspondence Editor for Neurology ${ }^{\circledR}$; is immediate Past President of the American Academy of Neurology; receives royalties from the publication of Andreoli and Carpenter's Cecil Essentials of Medicine, Eighth Edition (W.B. Saunders Company, 2000, 
2004, 2007, and 2010) and Cecil Textbook of Medicine, 24th Edition (Saunders, 2000, 2004, 2008, and 2010, in press); and has received research support from Taro Pharmaceuticals and the NIH/NINDS, the FDA, and the Muscular Dystrophy Association. Dr. Fontaine serves on the editorial board of Gene and Immunity and receives research support from sanofi-aventis, Institut National de la Santé et de la Recherche Médicale, Association Française contre les Myopathies, and Association pour la Recherche sur la Sclérose en Plaques. Dr. Sobue has served on scientific advisory boards for Kanae Science Foundation for the Promotion of Medical Science and Naito Science Foundation; serves on the advisory board of Brain and the editorial board of Degenerative Neurological and Neuromuscular Disease; and receives research support from the Ministry of Education, Culture, Sports, Science and Technology of Japan, the Ministry of Welfare, Health and Labor of Japan, and the Japan Science and Technology Agency, Core Research for Evolutional Science and Technology.

\section{Related articles from other AAN physician and patient resources}

\section{Neurology ${ }^{\circledR} \quad$ www.neurology.org}

Doctoring 2009: Embracing the challenge. October 13, 2009;73:1234-1239.

Global Perspectives. October 18, 2011;77:1565-1567.

Patient Page: The neurology world is flat. October 23, 2007;69:E16-E17.

\section{Neurology Now ${ }^{\circledR}$} www.neurologynow.org

Global Neurology Podcasts. http://journals.Iww.com/neurologynow/pages/podcastepisodes.aspx?podcastid=2

\section{Neurology Today ${ }^{\circledR} \quad$ - www.neurotodayonline.com}

Global Neurology: Neurologist Anthony Alessi, MD, in Haiti: A nation in recovery. October 6, 2011;11:43-45.

Global Neurology: Dr. Michael Earnest: On building health and the community in rural Haiti. October 6, 2011;11:43-44.

Global Neurology: Mateja de Leonni Stanonik, MD, PhD: Telemedicine pioneer and Slovenia's first Surgeon General.

September 1, 2011;11:17-18.

Global Neurology Podcasts.

http://journals.Iww.com/neurotodayonline/pages/podcastepisodes.aspx?podcastid=5 


\title{
Neurology ${ }^{\circ}$ Clinical Practice
}

\author{
Global imperatives and challenges facing the practice of neurology \\ Robert C. Griggs, Bertrand Fontaine and Gen Sobue \\ Neurol Clin Pract 2011;1;49-54 \\ DOI 10.1212/CPJ.0b013e31823b4e83
}

This information is current as of December 1, 2011

\begin{abstract}
Updated Information \&
Services

including high resolution figures, can be found at:

http://cp.neurology.org/content/1/1/49.full.html

References

This article cites 16 articles, 11 of which you can access for free at: http://cp.neurology.org/content/1/1/49.full.html\#\#ref-list-1

Subspecialty Collections

This article, along with others on similar topics, appears in the following collection(s):

All Practice Management

http://cp.neurology.org//cgi/collection/all_practice_management

Medical care

http://cp.neurology.org//cgi/collection/medical_care

Models of care

http://cp.neurology.org//cgi/collection/models_of_care

Professional conduct and ethics

http://cp.neurology.org//cgi/collection/professional_conduct_and_ethic $\mathrm{s}$

Permissions \& Licensing

Information about reproducing this article in parts (figures,tables) or in its entirety can be found online at:

http://cp.neurology.org/misc/about.xhtml\#permissions

Reprints

Information about ordering reprints can be found online: http://cp.neurology.org/misc/addir.xhtml\#reprintsus
\end{abstract}

Neurol Clin Pract is an official journal of the American Academy of Neurology. Published continuously since 2011, it is now a bimonthly with 6 issues per year. Copyright Copyright $\odot 2011$ by AAN Enterprises, Inc.. All rights reserved. Print ISSN: 2163-0402. Online ISSN: 2163-0933.

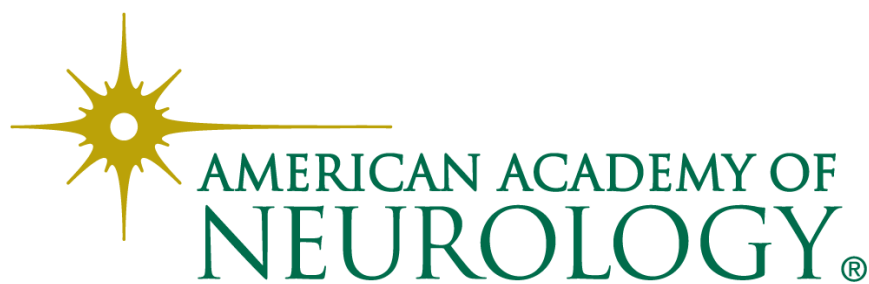

